\title{
Accounting for overspecification and indifference to visual accuracy in manuscript diagrams: A tentative explanation based on transmission
}

\author{
Christián C. Carman \\ Centro de Estudios de Filosofía e Historia de la Ciencia (CEFHIC), Universidad Nacional de Quilmes (UNQ), Pontifica \\ Universidad Católica Argentina (UCA), Consejo Nacional de Investigaciones Científicas y Técnicas (CONICET), Roque Sáenz. \\ Peña 352, B1876BXD Bernal, Buenos Aires, Argentina
}

\begin{abstract}
The first time you encounter a medieval manuscript of a Greek mathematical or astronomical work, like those of Archimedes, Euclid, or Aristarchus, the most impressive feature is the odd configuration many diagrams show. There is a tendency to represent more regularity among the geometric objects than what the argument demands and usually they are not accurate graphical depictions of the mathematical object discussed in the text. Most scholars believe that these tendencies go back to the Greek authors themselves. In this paper, I propose a different explanation: the odd characteristics should not be attributed to Greek authors, but to transmission.
\end{abstract}

(C) 2018 Elsevier Inc. All rights reserved.

MSC: 01A20; 01A35

Keywords: Manuscript diagrams; Transmission; Overspecification; Indiference to visual accuracy

\section{Introduction}

As is clear from the title of the book, in his On the Sizes and Distances of the Sun and Moon, Aristarchus of Samos obtains values for the sizes and distances of the Sun and Moon. Proposition 13, in which he obtains many ratios that he will use later, is the longest in the work. Aristarchus, as is usual for Greek mathematical authors, refers directly to the elements of the diagram: "[L]et the center of the sun be A, let $\mathrm{B}$ be the center of the earth, and $\mathrm{C}$ the center of the moon when the eclipses first becomes total, through the moon having fallen wholly within the earth's shadow" [Heath, 1913, 393]. The most ancient witness of the diagram that Aristarchus could have drawn is in the famous manuscript Vatican 204, f. 115r which was

E-mail address: ccarman@gmail.com.

0315-0860/๑ 2018 Elsevier Inc. All rights reserved. 


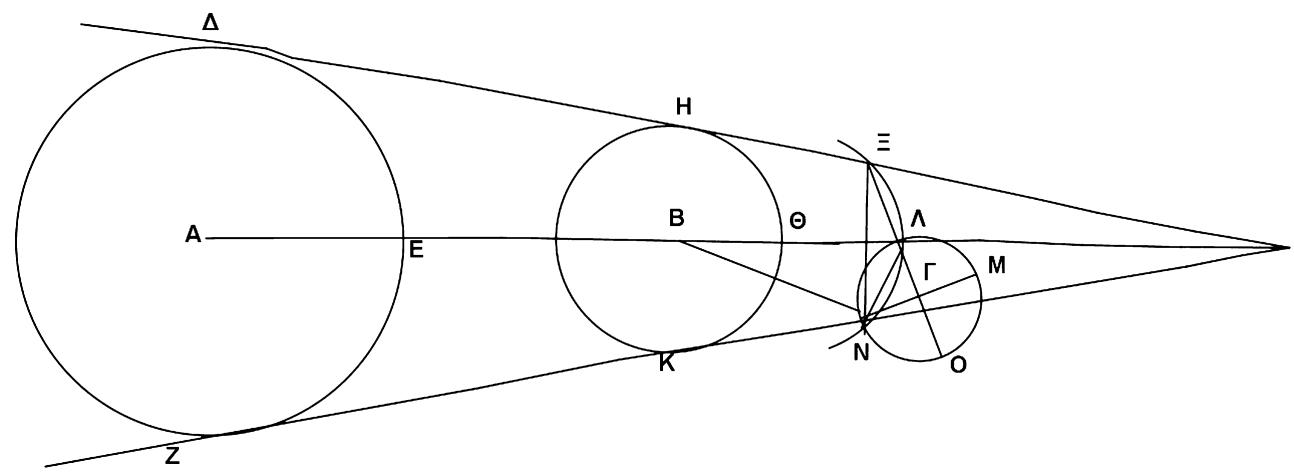

Figure 1. Diagram of proposition 13 of Aristarchus's On the Sizes and Distances of the Sun and Moon. Vatican 204, f. 115r.

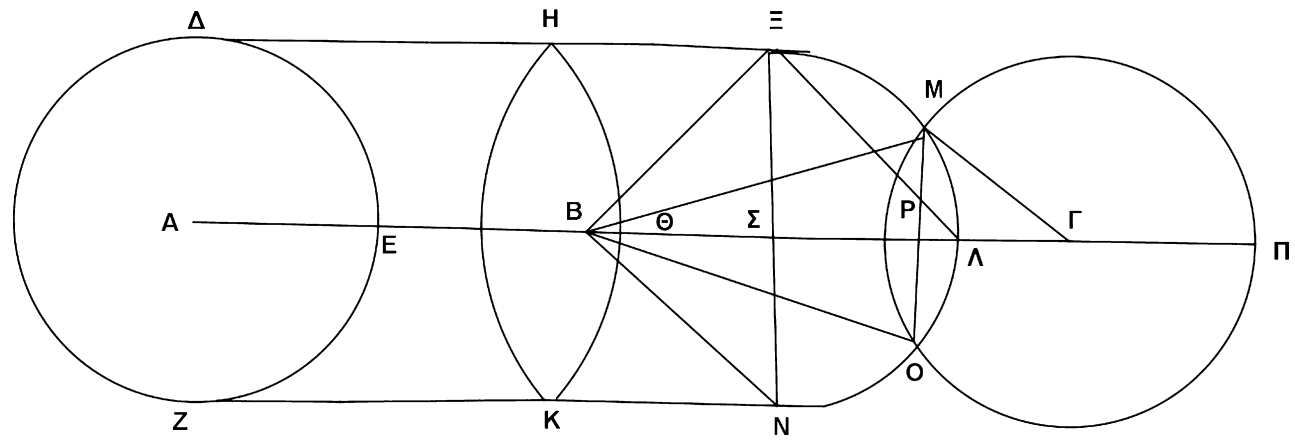

Figure 2. Diagram of proposition 14 of Aristarchus's On the Sizes and Distances of the Sun and Moon. Vatican 204, f. 116v.

composed more than one millennium after the original diagram. Nevertheless, the diagram is fairly clear and we, as modern readers, feel comfortable with it (see Figure 1).

The Sun is the biggest circle, centered at A, the Earth, smaller than the Sun, is centered at B. The tangents of both circumferences represent the rays of the shadow cone. The Moon, centered at $\Gamma$ and smaller than the Earth, is entering into the shadow cone, just as Aristarchus requires (even if it is not totally inside of it $^{1}$ ).

Aristarchus begins the following proposition by saying, "Let the same figure be drawn as before; and let the moon be so placed that its center is on the axis of the cone comprehending both the sun and the earth" [Heath, 1913, 393]. We assume that the figure should be similar to the previous one, but with the center of the Moon circle $(\Gamma)$ aligned with the centers of the Sun and Earth. Nevertheless, the figure is quite strange (see Figure 2).

The Earth is drawn as the same size as the Sun and, therefore, the rays of what should be a cone are now parallel, representing not a cone, but a cylinder. Even the Moon is drawn as the size as the Sun and the Earth. The arc $\Xi \mathrm{M} \Lambda \mathrm{ON}$, representing the Moon's orbit is so small that it is also the same size as the Moon, Sun, and Earth. Moreover, the center of this arc is not the Earth, but a point halfway between the surface of the Earth and that of the Moon. Finally, the Earth's circular shape assumes an unexpected lens shape. The same hand drew both diagrams, in the same manuscript, just one folio apart. ${ }^{2}$

\footnotetext{
1 For a discussion of this detail, see Berggren and Sidoli [2007] and Carman [2014].

2 For a discussion of these two figures and a proposal for explaining their divergences different to the one I offer below see Netz [1999, 40-41].
} 

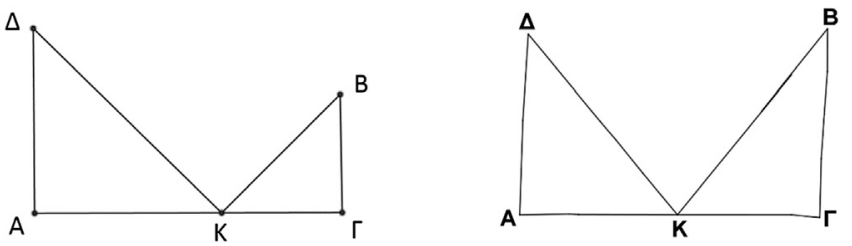

Figure 3. Diagram of proposition 1 of Euclid's Catoptrics. To the left, a diagram without overspecification reproducing [Heiberg and Menge, 1895, 7, 289]. To the right the diagram in Vatican 204, f. 135r.

Although most readers would be amazed with the odd features of Figure 2, scholars who are familiar with medieval manuscripts of Greeks scientific works, would probably be more amazed with Figure 1, because diagrams in manuscripts are often drawn incorrectly, like Figure 2.

The strange characteristics many diagrams have in medieval manuscripts were ignored for centuries, probably because the great majority of modern critical editions of Greek mathematical works silently re-drew the diagrams, ${ }^{3}$ obscuring their peculiarities from most scholars, who, confident on these critical editions, did not consult the manuscripts.

This situation changed in the last few decades, when scholars began to study the diagrams as they appear in the manuscripts with the same level of detail as the text itself. New critical editions of the diagrams and stemma codicum of manuscripts using the differences in diagrams have been published recently. ${ }^{4}$ There are also attempts to describe the main characteristics of the diagrams in manuscripts. The most systematic approach is that of Saito and Sidoli, who enumerate two main characteristics. ${ }^{5}$ According to them, many diagrams in manuscripts show what they call overspecification, i.e., "the tendency to represent more regularity among the geometric objects than is demanded by the argument. For example, we find rectangles representing parallelograms, isosceles triangles representing arbitrary triangles, squares representing rectangles, and symmetry in the figure where none is required by the text" [Saito and Sidoli, 2012, 140-141]. Another widespread tendency in the manuscript diagrams is the indifference to visual accuracy, i.e., "the use of diagrams that are not graphically accurate depictions of the mathematical object discussed in the text. For example, unequal lines may be depicted as equal [and] equal angles may be depicted as unequal" [Saito and Sidoli, 2012, 143]. ${ }^{6}$ Let me illustrate these characteristics with a few examples.

In proposition 1 of the Catoptrics, Euclid shows that in plane, convex, and concave mirrors, visual rays reflect at equal angles. The diagram that I will analyze corresponds to plane mirrors. See Figure 3, left. The mirror is line $\mathrm{A} \Gamma$, the eye is at $\mathrm{B}$. The ray $\mathrm{BK}$ meets the mirror at point $\mathrm{K}$ and is reflected to the ray $\mathrm{K} \Delta$. Angles $\mathrm{BK} \Gamma$ and $\Delta \mathrm{KA}$ are equal. Even if the argument does not require that $\mathrm{K}$ is equidistant from $\mathrm{A}$ and $\Gamma$, this is the case in the diagram of the manuscript (see Figure 3, right). The proof of the proposition is based on the similarity between triangles BKГ and $\triangle \mathrm{KA}$. Nevertheless, in the diagram of the manuscript

\footnotetext{
3 Neugebauer [1975, 751-755] complained about the failure of classical scholars to pay attention to the manuscript diagrams. This is not totally fair. See for example Heiberg's edition to Theodosius Spherics [Heiberg, 1927]; the edition of Besthorn et al. [1897-1932] of al-Nayrizi's commentary to the Elements; Menge [1916, 1-112] in his comments to Euclid's Phenomena; the edition by Rome [1931-1943] of the Commentaries of Pappus and Theon on Ptolemy's Almagest; Mogenet [1950] on Autolycus's treatises, Lejeune [1989] on Ptolemy's Optics. For more references, see Sidoli [2007, n. 4].

4 See, for example, Jones [1986], Czinczenheim [2000], Netz [2004], Raynaud [2014], and Raynaud [2016, 256-261].

5 There are other differences that I will not analyze in this paper, such as the use of impossible figures for proofs by reductio ad absurdum and the use of one figure for representing many different cases [Saito, 2012, 8].

6 The term 'overspecification' has been introduced by Saito [2006, 82]. He also talks about "standardized" diagrams for overspecification and that "Metrical correctness is not so important" for indifference to visual accuracy [Mascellani et al., 2005, 74]. Raynaud [2014, 208-209] also summarizes the main characteristics: the diagrams are schematized whenever possible; the figures are usually overspecified and linear values in the diagrams are not necessarily faithful to the mathematical content.
} 

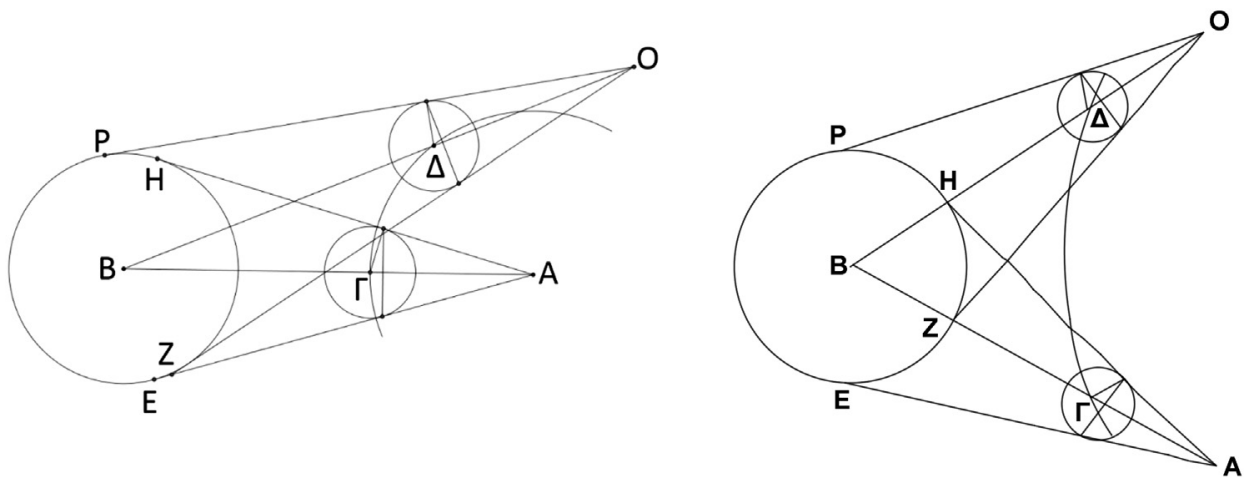

Figure 4. Diagram of proposition 3 of Aristarchus's On the Sizes and Distances of the Sun and Moon. To the left, a mathematically correct diagram inspired by Heath [1913, 362]. To the right, the diagram in Vatican 204, f. 110v. Some letters have been omitted to make the figure clearer.

(taken also from Vatican 204, f. 135r.), they are not only similar, they are equal. Even if technically this is not wrong (after all, equal triangles are similar also), this is more than what is required.

In this example, therefore, the overspecification of the diagram does not make it inaccurate. But this is the case in many other diagrams. For example, in the diagram of proposition 3 of Aristarchus's already mentioned On Sizes, (see Figure 4) the Sun is centered at B, the observer is at A, and the Moon is depicted in two different positions: 1) centered at $\Gamma$ when the three (Sun, Moon and Earth) are aligned, and 2) centered at $\Delta$ when they are not aligned. Both centers are equidistant from $\mathrm{A}$, because the Moon revolves around the Earth in a circular orbit. Aristarchus wants to show that the terminator (i.e., the line that divides the dark and the bright portions of the Moon represented by the lines that, being inside the lunar circles, are perpendicular to the axes) is least when the three are aligned than in any other position. To do this, he explicitly shows that the height of the cone with vertex in A is smaller than that of the cone with vertex in O. Nevertheless, both cones are equal in the diagram of the manuscript (again, taken from Vatican 204, f. 110v.). Therefore, the diagram of the manuscript is not only overspecified, but also indifferent to visual accuracy. ${ }^{7}$

Another example is found in a diagram of Ptolemy's Almagest, V.17, where he shows how to calculate the values for the lunar parallax table [Toomer, 1988, 263, Figure 5.15]. See Figure 5. The circle centered in $\mathrm{E}$ is the deferent of the Moon, which is eccentric because the observer is at $\mathrm{Z}$. The Moon is at B. In this particular case, Ptolemy wants to calculate the parallax when the elongation of the Moon is $30^{\circ}$. Line $\mathrm{HE}$ is perpendicular to $\mathrm{B} \Delta$. Because angle $\mathrm{AZB}$ doubles the elongation, he explicitly takes the angle $\mathrm{AZB}$ as $60^{\circ}$. In the diagram of the manuscript (taken from Vatican 180, f. 129r.), however, angle AZB looks like a right angle, and line $\mathrm{HE}$ is not perpendicular to $\mathrm{B} \Delta$.

The inaccuracy in the last two examples seems to be due to some tendency to symmetry that makes the height of the two cones equal and the base $\mathrm{B} \Delta$ of the triangle perpendicular to $\mathrm{A} \Gamma$, the axis of symmetry. In some other diagrams, however, the inaccuracy cannot be justified invoking symmetry. In these cases we are dealing with indifference to visual accuracy simpliciter. This is the case of the diagram of proposition 2 of Euclid's Optics. ${ }^{8}$ Euclid shows that objects located nearby are seen more clearly than objects of equal size

\footnotetext{
7 Actually, if overspecification only applies to diagrams where the figure is more regular than required but, still, mathematically correct, then the two-cone diagram is not a case of overspecification, because it is mathematically incorrect to draw the two cones with equal height. Therefore, this diagram would be a case of indifference to visual accuracy, but then the tendency towards greater regularity does not belong exclusively to overspecification. If the tendency to symmetry or regularity keeps the diagram mathematically correct, then, it would be a case of overspecification, if not, it would be a case of indifference to visual accuracy.

8 There are two versions of the text, both edited by Heiberg and Menge [1895], the first titled Euclidis Optica (pp. 1-121) and the second Opticorum Recensio Theonis (pp. 143-247). The diagram I use belongs to Vatican 204, the oldest manuscript of the second version. See Jones [1994] and Knorr [1994].
} 

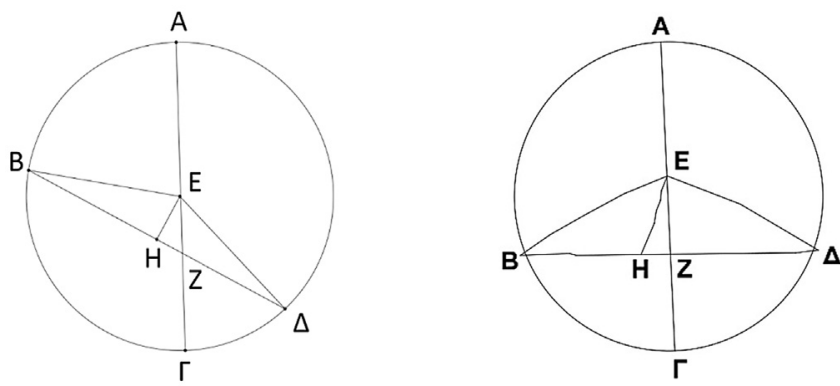

Figure 5. Diagram from Ptolemy's Almagest, V. To the left, a mathematically correct diagram reproducing Figure 5.15 of Toomer $[1988,263]$. To the right, the diagram in Vatican 180, f.129r.
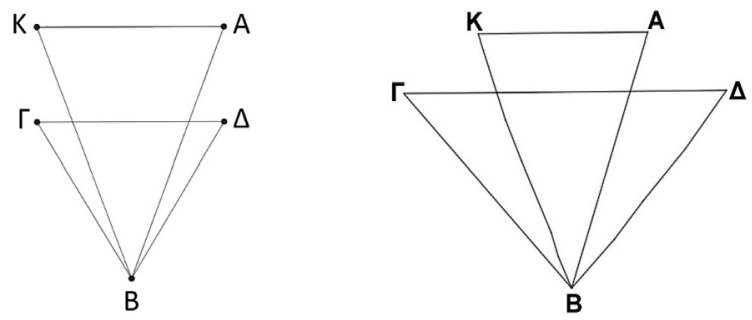

Figure 6. Diagram of proposition 2 of Euclid's Optics. To the left, a mathematically correct diagram due to Heiberg and Menge $[1895,7,4]$. To the right, the diagram in Vatican 204, f. 44v.
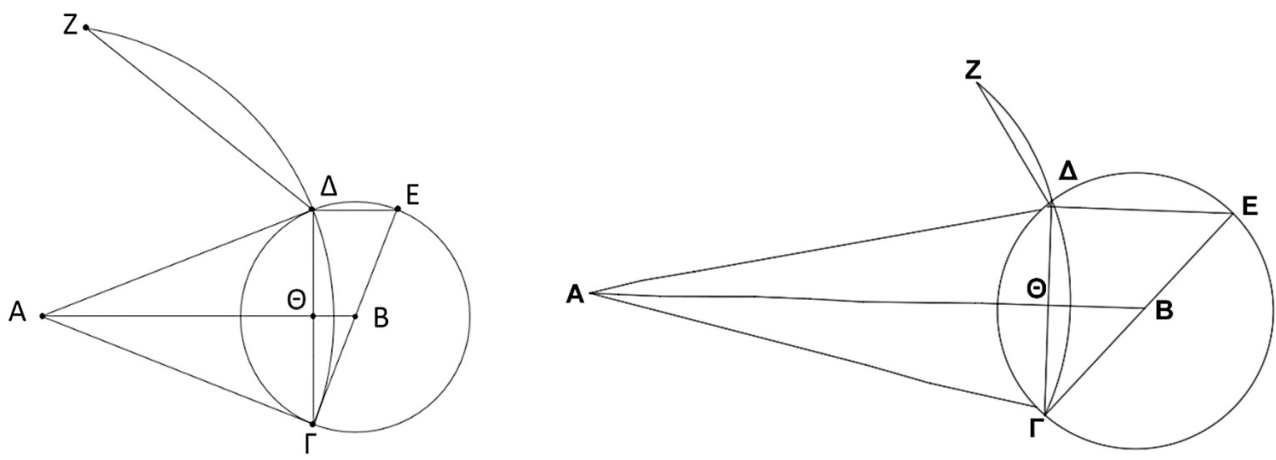

Figure 7. Diagram of proposition 11 of Aristarchus's On the Sizes and Distances of the Sun and Moon. To the left, a mathematically correct diagram inspired by that of Heath [1913, 387]; to the right the diagram in Vatican 204, f. 114r.

located at a greater distance. See Figure 6 . In the diagram, the eye is at $\mathrm{B}$, and lines $\Gamma \Delta$ and KA represent the objects seen. They are, therefore, equal and parallel. Nevertheless, in the diagram of the manuscript (Vatican 204, f. 44v.), $\Gamma \Delta$ is considerably longer than KA.

Another case of indifference to visual accuracy that cannot be related to symmetry can be found in the diagram of proposition 11 of the Aristarchus's On Sizes (see Figure 7). In this diagram the Moon is centered at $\mathrm{B}$ and the observer is at $\mathrm{A}$. Aristarchus compares the diameter of the Moon ( $\mathrm{E}$ ) with the distance from the Earth to the center of the Moon (line AB). For making this comparison, he constructs one side of a hexagon $(\Delta \mathrm{Z})$ inscribed in the circle with center $\mathrm{A}$ and radius $\mathrm{A} \Gamma$. This is because the sides of a hexagon inscribed in a circle are equal to the radius of the circle, i.e., $\mathrm{A} \Delta=\Delta \mathrm{Z}$. This fact is explicitly used in the argument. In the diagram of the manuscript (Vatican 204, f. 114r.), however, $\Delta \mathrm{Z}$ is clearly smaller than $\mathrm{A} \Delta$. 
These are only a few illustrative examples of hundreds that are available in manuscripts. Considering that, except for very few testimonies extant in papyrus (from which not much can be inferred ${ }^{9}$ ), the most ancient witnesses of Greek diagrams are medieval, we cannot conclusively decide whether these characteristics go back to the Greek authors or they are the result of medieval copyists. The dominant position among scholars today is that these characteristics go back to the Greeks themselves. Usually, the main reason is that they are so prevalent in the Greek, Arabic, and Latin transmissions that it could not but reflect ancient practice [Saito and Sidoli, 2012, 143]. ${ }^{10}$

I will offer an alternative explanation: the odd characteristics of medieval representation of ancient diagrams are not due to the Greek authors themselves. Independently of how they drew the original diagrams, the successive copies that diagrams underwent, century after century, from their original version up to the most ancient preserved copy, gradually deformed the diagrams until acquiring the overspecification and indifference to visual accuracy that manuscripts testify. It is obvious that small modifications would accumulate from copy to copy. What my hypothesis requires is much stronger: I must show that starting from the supposed original diagram (that is, the diagram well done), a series of copies will generally transform it into a diagram similar to that of the manuscripts. That is, I must show not only that there is some cumulative change copy after copy, but that there is a tendency in the changes towards the characteristics that appear in the manuscript's diagram.

To test this hypothesis I asked many groups of university students to play the role of copyists. Most students come from psychology, philosophy, literature, engineering, and business administration degrees, both at public and private universities of Argentina. ${ }^{11}$ In each group, around 20 students were placed in a circle. I gave a folder to one of them, containing a drawing of the diagram as I presume the Greek author drew it.

\footnotetext{
9 Commenting on the diagram of Apollonius's Conica I, 16 [Heiberg, 1891-1893, 65], Eutocius noticed the overspecification of this diagram, and suggested that it be avoided (see Decorps-Fulquier [1999, 74-75] and Saito and Sidoli [2012, 145]). This text shows that overspecification was present in effect at least since the sixth century. There are some diagrams in papyri from the first centuries A.D., mainly from Euclid's Elements. But most of them are probably simply teacher's notes or even student's notes, and not "official" copies [Sidoli, 2015, 392-393], therefore it is not safe to draw any conclusion from them. For discussions of these diagrams see Netz [2015, 299-301], and Fowler [1999, 209-217].

10 Netz [2004, 5] also defends that in some cases medieval diagrams "may represent the diagrams as available in late antiquity and, possibly, at least in some cases, as produced by Archimedes himself". Netz is talking particularly about some chords that are represented by arcs in medieval diagrams of Archimedes. In this case, he does not argue, like Saito, from the universality of the fact, but from the manuscript authority. Netz and Noel [2007, 100-101] are more emphatic: "This is how he, Archimedes, traced his figure, turning a stick in his sand. ... Those are traces left by him, personally ... First of all, no one would dare introduce such a radical convention against the manuscript authority. Suppose you were a scribe and paid to copy diagrams from the original The original has polygons. Well, you would copy them as polygons. You would not invent circular arcs instead. And this reason that no one would introduce such a convention against the source - can be repeated and again for each stage of the transmission The only way to account for such a convention is to assume that it is due to the author himself'. Later, Netz [2012, 165] seems somewhat more skeptical, even if, by the end of the paper, he repeats his argument concerning the arc shape of the sides of the polygon. If ancient authors drew their diagrams with overspecification and indifference to visual accuracy, then there must be a reason, for this is not what one would a priori expect. For Netz "the diagrams are non-pictorial. You draw a polygon, but you do not make your drawing look like one. Instead of being a picture, the ancient diagram is a schematic representation" [Netz and Noel, 2007, 101, italics in the original]; see also Netz [2004, 9]. According to Saito and Sidoli [2012, 157] on the one hand, "[t]he consistent use of overspecification implies that the diagram was not mean to convey an idea of the level of generality discussed in the text. The diagram simply depicts some representative example of the objects under discussion", on the other, "the indifference to visual accuracy implies that the diagram was not meant to be a visual depiction of the objects under discussion but rather to use visual cues to communicate the important mathematical relationships. In this sense, the diagrams are schematic representations."

11 It is reasonable to assume that most copyists drawing the diagrams (who usually did not copy the text) did not understand the mathematical content of the text. Hence, I decided not to introduce the mathematical content of the diagrams to the students. It is true, however, that there were some copyists who did understand the content during transmission. For example, most of Euclid's Elements manuscripts come from Theon's emendation, who certainly understood the text. Nevertheless, as I will show in the following pages, the tendency to overspecification and indifference to visual accuracy is so strong during transmission that, one can presume that if the diagrams were completely re-drawn avoiding these tendencies, they would rise again after a few copies.
} 
I asked the student to copy the diagram and to place her copy in the folder, over the starting diagram she had copied before hiding it, and to pass the folder to the next student, who would copy the drawing made by the first student, and so on. I asked the students to copy the diagrams as faithfully as possible, using all the tools available to them. The great majority of them used ruler or similar objects for making straight lines, but practically no one used a compass, even if sometimes they used circular objects, such as a glass or a coin to draw circles. ${ }^{12}$ In general, the experiment was repeated around 10 times for each diagram analyzed, obtaining about 10 sets of 20 copies. I analyzed 13 diagrams, involving around 2600 drawings. In what follow, for brevity, I will present the results of 5 diagrams; the rest are available online (https://goo.g1/B2f1Pd).

The results can be divided into two main groups: analyzable and unanalyzable. Some series reached a point where the figure was so distorted that the characteristic that I wanted to analyze had disappeared and become, thus, unanalyzable. For example, if I wanted to measure the ratio between two sides of a triangle, but the triangle itself disappeared. Sometimes it happened by small successive deformations but usually by a particularly careless student. The number of unanalyzable series depends, to a large extent, on the difficulty of the diagram. Some examples are available online (https://goo.gl/B2f1Pd).

Most of the series, however, are analyzable: i.e., the variable that I wanted to measure was preserved. In many cases this variable converged to the characteristic of the manuscript's diagram (for example, the unequal heights of two different cones became equal), while in others the variable either a) remained like in the starting diagram, i.e., more or less stable, or b) was deformed, but not as expected, i.e., towards the characteristic showed in the manuscripts (for example, the different height of the two cones became increasingly greater).

A critical decision of the experiment is, of course, the selection of the first diagram from which the series of copies will start; after all, we do not have the original diagram. There are many ways in which a diagram can be drawn so as to be mathematically correct and according to our modern standards. I selected the diagrams from the most trustworthy modern editions. ${ }^{13}$

For each diagram analyzed, I offer a witness series as an example with one complete set of drawings, together with a chart that summarizes the results. In the upper right corner of the chart I indicate a) the number of series that support my hypothesis, b) the number of series that do not support my hypothesis, and c) the number of unanalyzable series.

The results are very persuasive even to a naked-eye inspection of the witness series. Nevertheless, to make the results as objective as possible and to be able to handle many series at the same time, I quantified the variation of the characteristic for which I tested. For example, from the Almagest's diagram mentioned above I want to test whether the base of the triangle $\mathrm{B} \Delta \mathrm{E}$ becomes perpendicular to line $\mathrm{A} \Gamma$. Therefore, in each drawing of the series I measured angle AZB. In Aristarchus's diagram with the two cones, I measured the ratio between segments $\mathrm{BO}$ and $\mathrm{BA}$ (the distance between the center of the Sun, $\mathrm{B}$, and the vertices of both cones, $\mathrm{O}$ and $\mathrm{A}$ ). Here, and in all cases where ratios are involved, the logarithm of the ratio is used to represent this graphically, as it makes the ratios symmetrical. In the chart of each diagram I plot the variable, starting from the value of the starting diagram and finishing in the twentieth copy. The unsupporting series are individually plotted in dark gray, the supporting series in light gray and dotted lines, except for the

\footnotetext{
12 It could be objected that this vitiates the experiment for there is evidence from medieval manuscripts that copyist usually (even if it is clear that it was not always the case) drew the circles and arcs using compasses. One must remember, however, that what is in question here is the transmission from the original diagram up to the oldest extant medieval copy. Still, there is no certain evidence to affirm that the standard practice among Classical and Hellenistic copyist was to use compasses for drawing circles. In any case, there is just one change in my analysis (including the cases of the appendix) that involves a circle, that of the Earth's circumference in diagram of proposition 14 of Aristarchus's On Sizes that becomes a lens-shape figure. All the other changes do not involve circles and, therefore, this objection would not affect them. Future tests using compass would be desirable. I thank one of the anonymous referees for bringing forward this objection.

13 Heiberg for Euclid's Optics and Catoptrics, Toomer for Ptolemy's Almagest, and Heath for Aristarchus's On Sizes. I specified the bibliographic references in the figure of each diagram.
} 


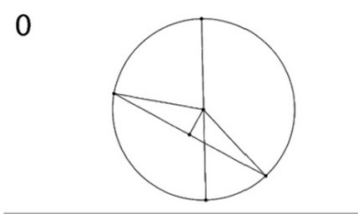

3

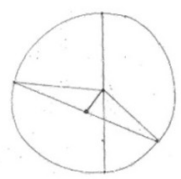

6

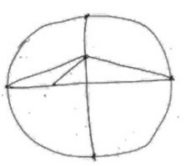

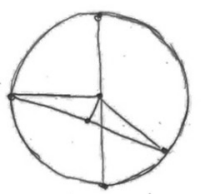

4

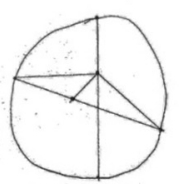

7

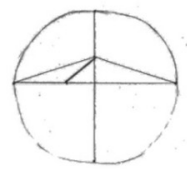

2

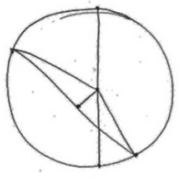

5

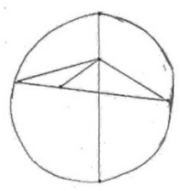

8
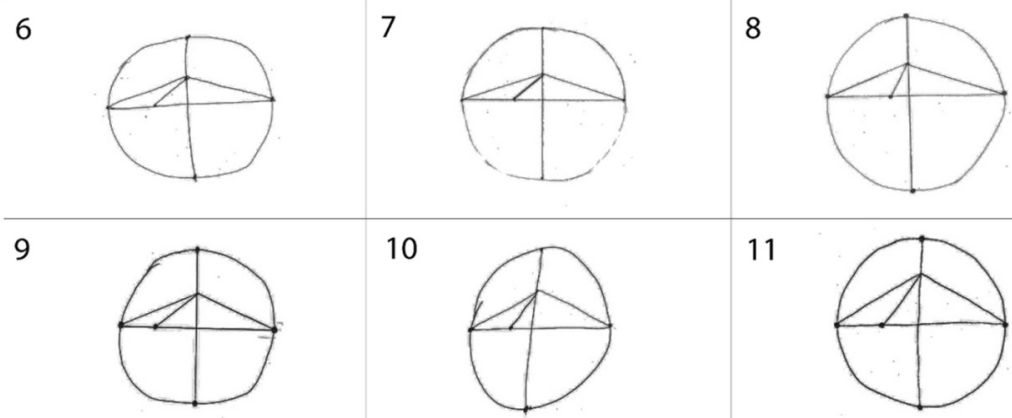

10

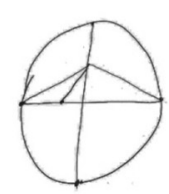

11

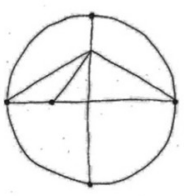

12

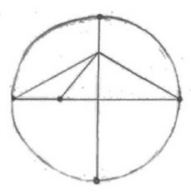

13

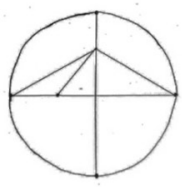

15

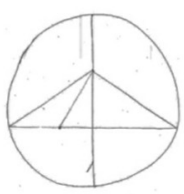

16

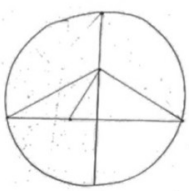

19

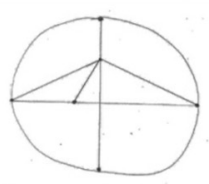

\section{4}

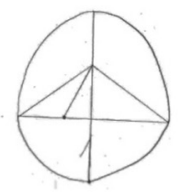

17

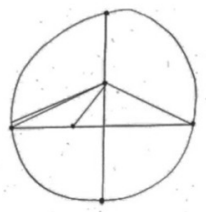

M

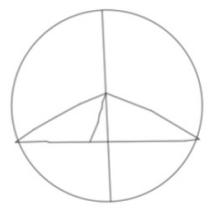

Figure 8. Reproduction of a witness series of the drawings copying a diagram of the V book of Ptolemy's Almagest. Starting diagram (0): Figure 5.15 of Toomer [1988, 263]; final diagram (M): Vatican 180, f. 129r. The drawings have been rotated and resized to fit in the assigned space.

one that has been selected as witness and shown in the figure, which is plotted with a solid gray line. The average of all the supporting series is plotted in black, to favor a comprehensive view of the positive results.

\section{The results}

In the diagram of the Almagest mentioned above I measure angle AZB at $60^{\circ}$, the angle of the starting diagram, taken from Toomer [1988, 263, Figure 5.15]. The diagram of the manuscript was taken from Vatican 180, f. 129r.

Let me start by analyzing the witness series (Figure 8). Drawing 0 is the starting diagram, which the first student copied. Her copy is labeled 1; the one that copies her drawing, 2, and so on. In the starting diagram 


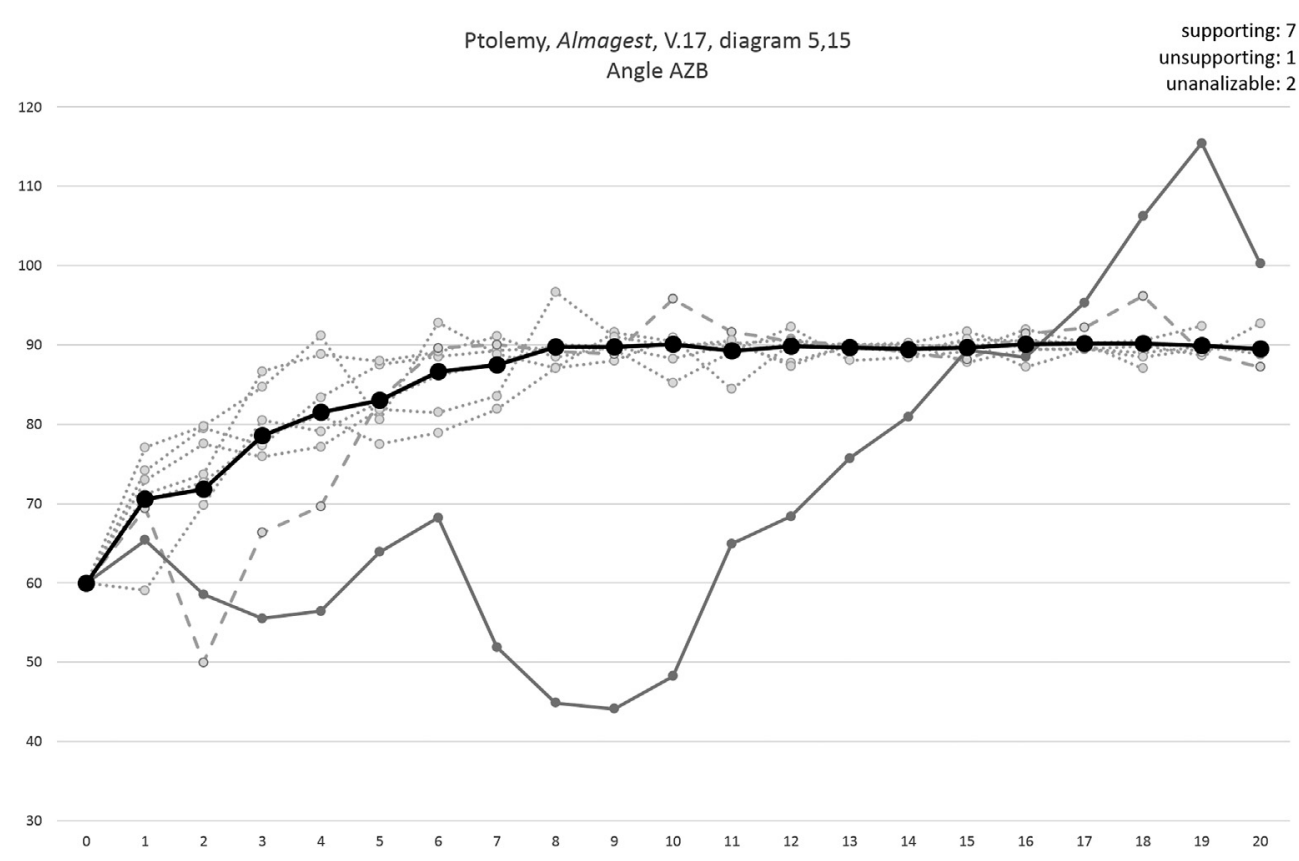

Figure 9. The chart shows the change throughout the copies of angle AZB belonging to the diagram 5,15 of Ptolemy's Almagest, V.17. The unsupporting series is individually plotted in dark gray, the supporting series are plotted in light gray and dotted lines, except for the one that has been selected as witness and shown in Figure 8, which is plotted with a solid gray line. The average of all the supporting series is plotted in black.

the base of the triangle $\mathrm{B} \Delta \mathrm{E}$ is clearly oblique with respect to the vertical diameter $\mathrm{A} \Gamma$ and remains so in the first 5 copies, but as early as in the sixth or seventh copy the base of the triangle is perfectly perpendicular to $\mathrm{A} \Gamma$. This new configuration is preserved throughout the subsequent copies, up to the end. So, starting the experiment with the base of the triangle tilt at $60^{\circ}$ with respect to the vertical line $\mathrm{A} \Gamma$, one rapidly obtains the base of the triangle positioned vertically with respect to $\mathrm{A} \Gamma$. Most importantly, this characteristic is preserved over the following copies: once the manuscript-shape is obtained it is preserved for all the copies of the series (and I will show that this generally happens). In other words: the manuscript-type diagram is stable. This explains why, copy after copy, the diagram has not been distorted in all the extant manuscripts, preserving the base of the triangle $\mathrm{B} \Delta \mathrm{E}$ vertical with respect to line $\mathrm{A} \Gamma{ }^{14}$

The experiment for this diagram was done 10 times, obtaining 10 series. Two series were unanalyzable, 7 produced results that support my hypothesis and there was only 1 unsupporting series, i.e., in 7 series the base of the triangle turned perpendicular to $\mathrm{A} \Gamma$, while in 1 it did not. The result, as is shown in the graph, supports my hypothesis (see Figure 9). The average of the supporting results shows that around copy 8 all the supporting series had already arrived at the objective, and they preserve its features over the remaining copies. Therefore, it is likely that if Ptolemy did the diagram correctly, i.e., with an angle of $60^{\circ}$ between lines $\mathrm{HE}$ and $\mathrm{B} \Delta$, the transmission process would have made the two lines perpendicular, probably sooner rather than later. Let me move to the next diagram.

In the diagram of proposition 3 of Aristarchus's On Sizes, I calculated the logarithm of the ratio between segments BO and BA. It starts greater than 0 and should arrive at 0 . The starting diagram was inspired by that of Heath [1913, 362], and the diagram of the manuscript was taken from Vatican 204, f. 110v (see Figure 10).

$\overline{14}$ Nevertheless, as I hope to show in a forthcoming paper, some small changes can be detected in manuscripts. 


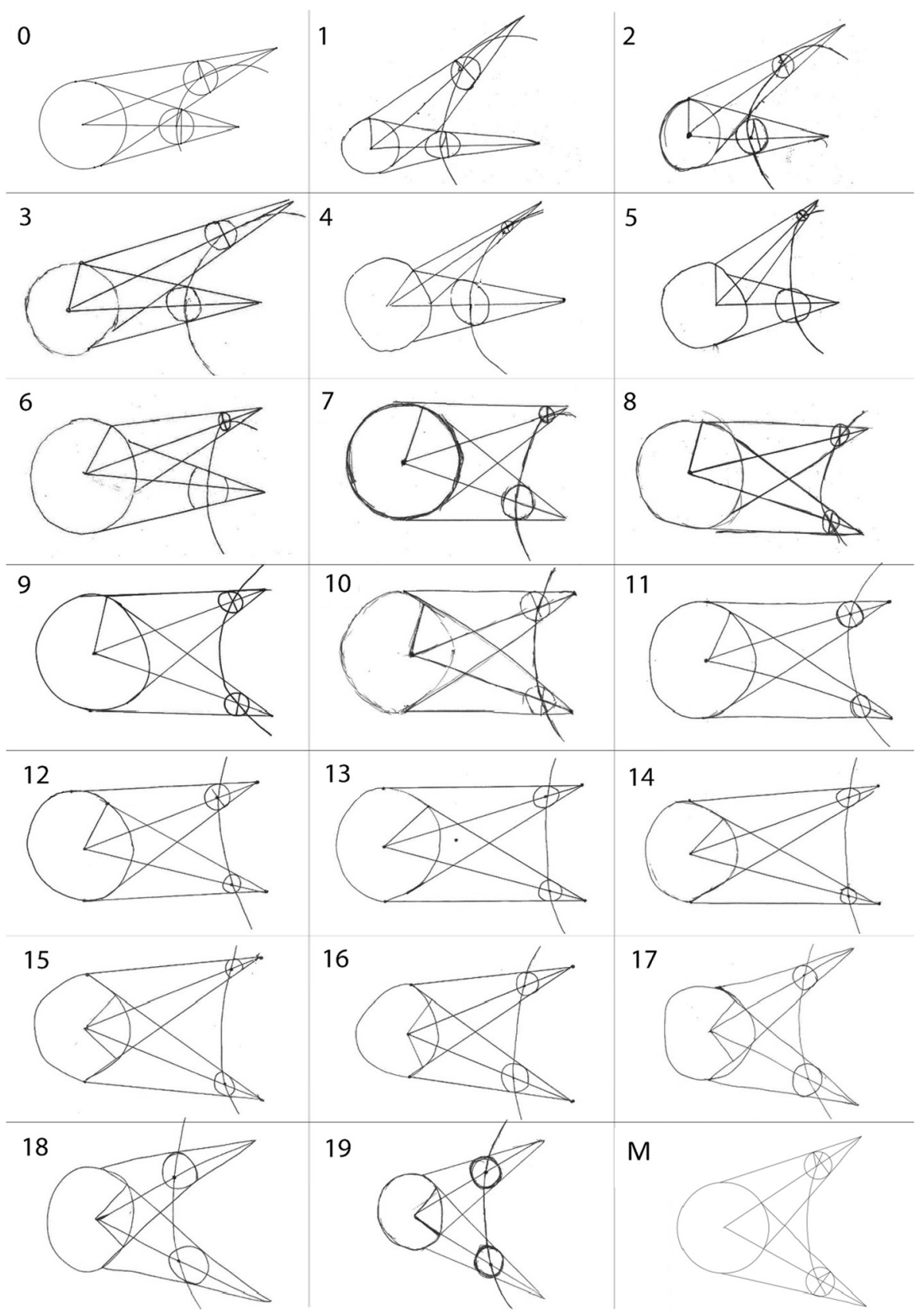

Figure 10. Reproduction of a witness series of the drawings copying the diagram of proposition 3 of Aristarchus's On the Sizes and Distances of the Sun and Moon. The starting diagram (0), inspired by Heath [1913, 362]; final diagram (M): Vatican 204, f. 110v. The drawings have been rotated and resized to fit in the assigned space.

The results are similar to those of the previous diagram: among 11 series, 3 had to be discarded, 7 support my hypothesis, while only 1 does not (see Figure 11). The equality of the axes of the two cones is obtained fairly quickly, and in 3 series, as early as in the second copy. Once again, there is a strong tendency in the transmission to make the height of the two cones equal.

My third case analyzes the diagram of proposition 2 of Euclid's Optics (Figure 12), in which I measured the ratio between the two lines representing the objects which must be equal: $\Gamma \Delta / \mathrm{K} \Lambda$, and I plotted the 


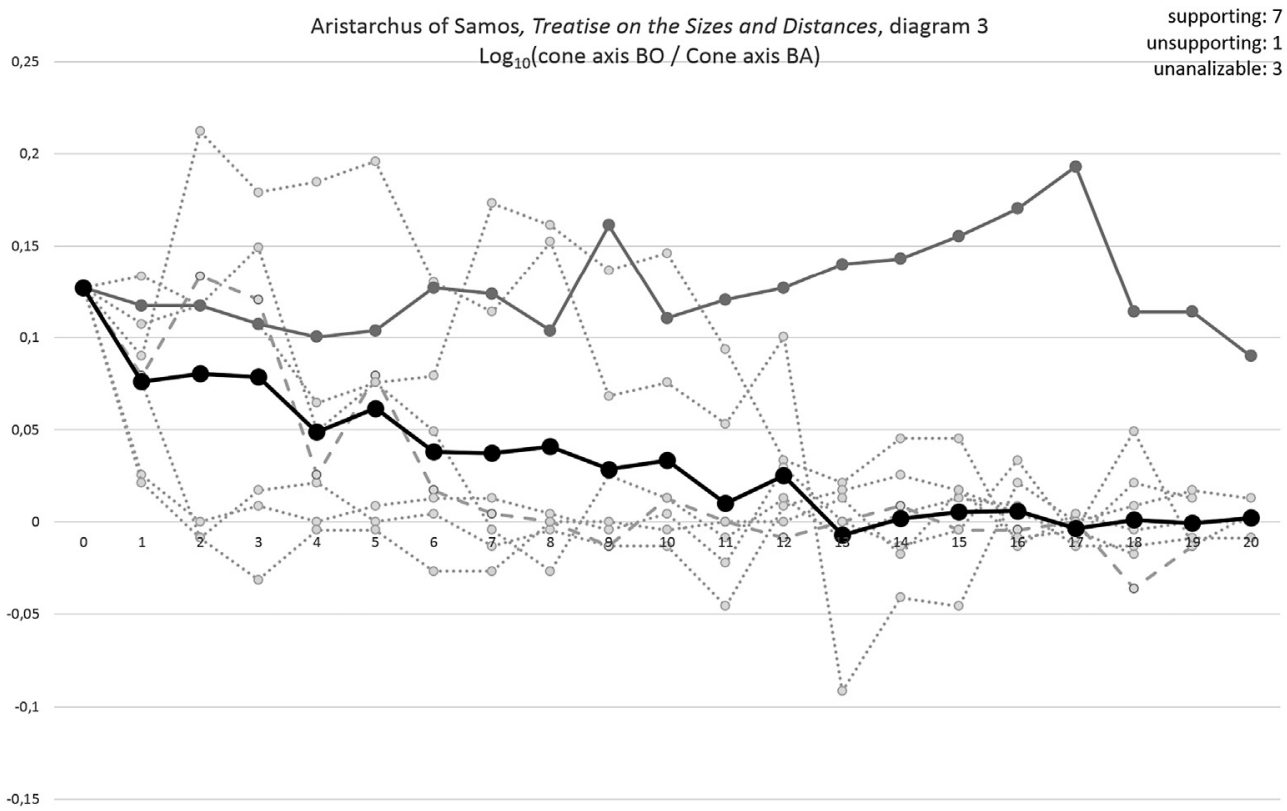

Figure 11. The chart shows the change throughout the copies of the logarithm of the ratio between cone axis BO and cone axis BA of the diagram of the proposition 3 of Aristarchus's On Sizes. The unsupporting series is individually plotted in dark gray, the supporting series are plotted in light gray and dotted lines, except for the one that has been selected as witness and shown in Figure 10 , which is plotted with a solid gray line. The average of all the supporting series is plotted in black.

logarithm of this ratio (see Figure 13). It starts at 0 and should finish greater than 0 . The starting diagram was taken from Heiberg and Menge [1895, 7, 156], while that of the manuscript from Vatican 204, f. $44 \mathrm{v}$. In this case, I obtained 8 series of which 2 had to be discarded, with the remaining 6 supporting my hypothesis, so I obtained 100\% support of my hypothesis in the analyzable series. In all cases except one, the inequality of both lines was obtained in the very first copy. It is important to notice that the experiment could produce opposite results in different kinds of diagrams: the previous case started from cones of different heights and arrived at cones with the same height (Figure 10); this case started from equal lines obtaining unequal lines (Figure 12). Therefore, it is clear that the effect of the transmission is not limited to overspecification, or cases of indifference to visual accuracy producing symmetries, but cover also cases of indifference to visual accuracy that produce asymmetries. The same feature will be patent in the next case.

The fourth case analyzes the diagram of proposition 11 of Aristarchus's On sizes (Figure 14), in which I measured the ratio $\mathrm{A} \Delta / \Delta \mathrm{Z}$ and I plotted its logarithm, which starts at 0 (when both segments are equal) expecting it to increase as the copies are made (see Figure 15). I have drawn the starting diagram in a similar fashion to that of Heath [1913, 387], and the diagram of the manuscript was taken from Vatican 204, f. 114 r.

Of 9 series, 3 had to be discarded because they were unanalyzable. The 6 analyzable series support my hypothesis. As the chart clearly shows, around the third copy of each series line $\Delta \mathrm{Z}$ is shorter than line $\mathrm{A} \Delta$. Therefore, here again we have a case in which transmission produces indifference to visual accuracy not related to symmetry.

For my last example, I analyzed the diagram of proposition 14 of Aristarchus's On Sizes. The series started with a diagram of proposition 14 , which $\mathrm{I}_{\text {drew }}{ }^{15}$ with an angle between both shadow rays $(\Delta \mathrm{H}$

$\overline{15}$ I did not use Heath's diagram because he fused two diagrams that are separate in the manuscripts. 


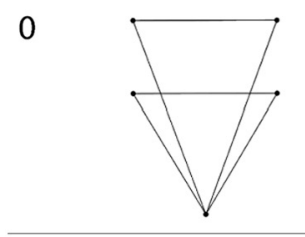

3

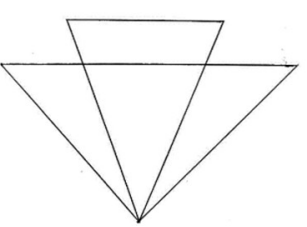

6

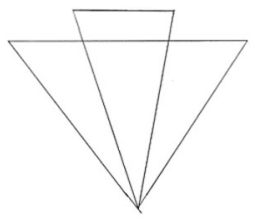

9

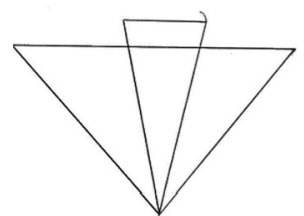

12

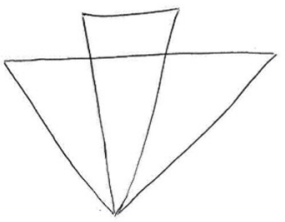

15

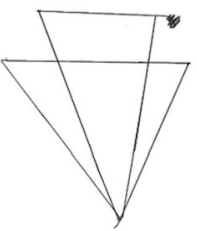

18

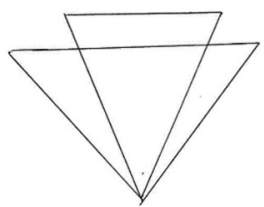

1

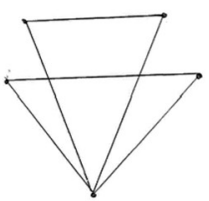

2

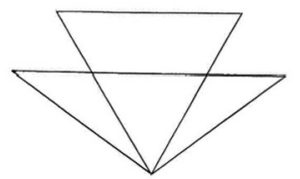

5

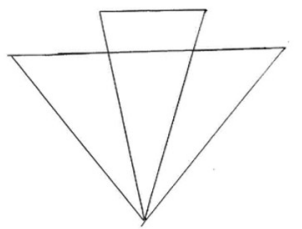

8

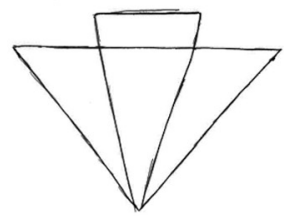

11

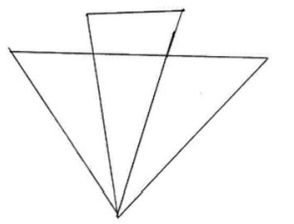

13

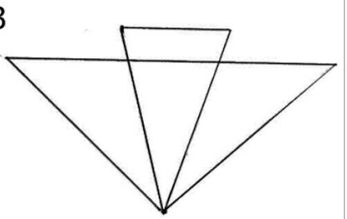

14

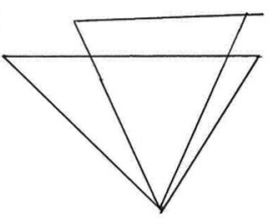

17

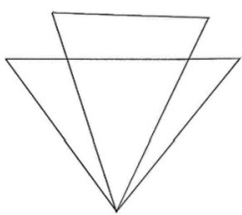

M

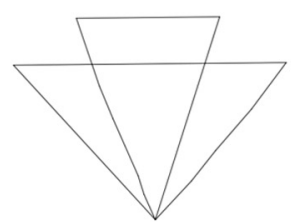

Figure 12. Reproduction of a witness series of the drawings copying the diagram of proposition 2 of Euclid's Optics. Starting diagram (0), reproducing that of Heiberg and Menge [1895, 7, 156]; final diagram (M): Vatican 204, f. 44v. The drawings have been rotated and resized to fit in the assigned space.

and ZK) of $5.14^{\circ}$ (see Figure 16). This angle could be considered too small (even if the shadow rays are clearly perceived not to be parallel), but I made it this size in order to be able to draw all lines as clear as possible. ${ }^{16}$ The diagram of the manuscript was taken from Vatican 204, f. 116v.

\footnotetext{
$\overline{16}$ I also did the same experiment but with a greater angle between the shadow rays $\left(20^{\circ}\right)$ and it the results also supported my hypothesis. See online Appendix, 6.
} 


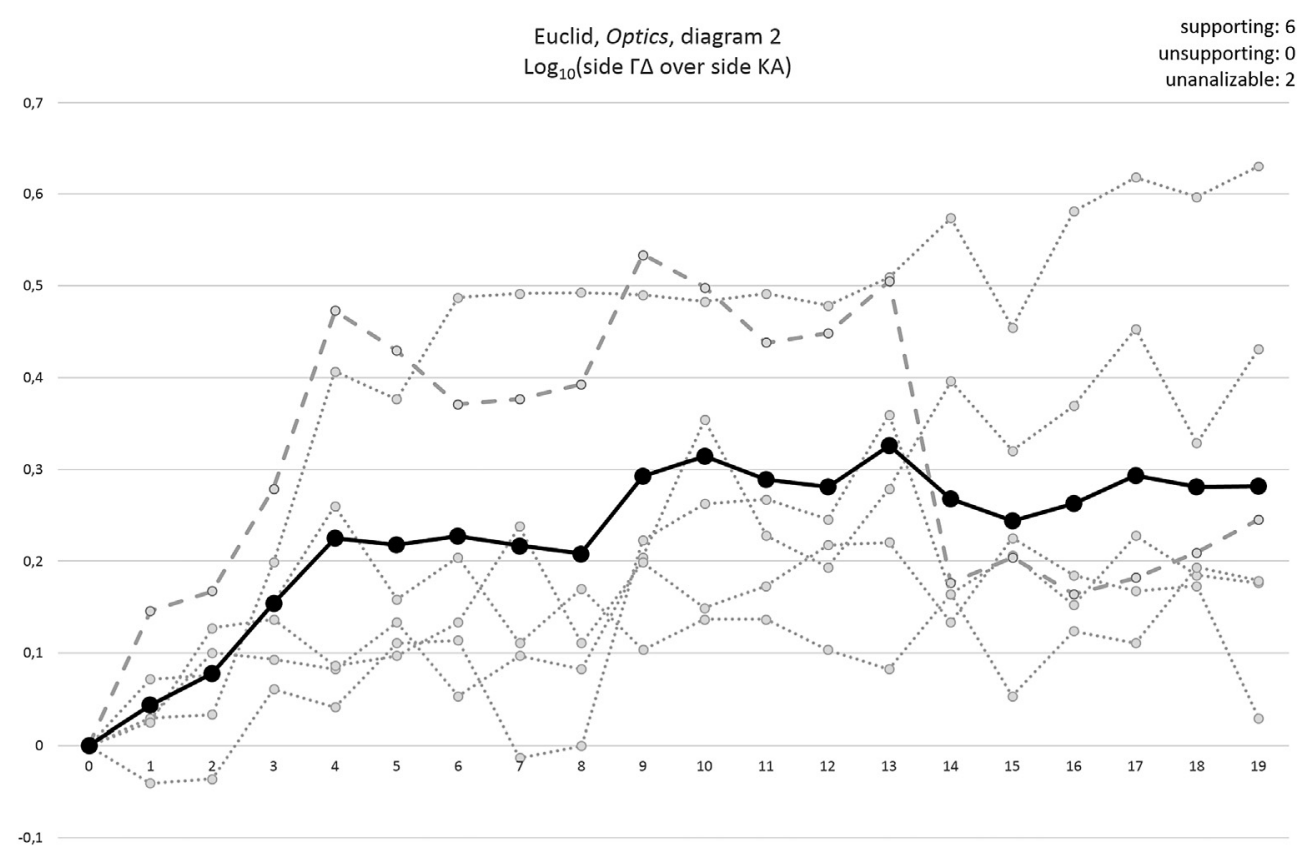

Figure 13. The chart shows the change throughout the copies of the logarithm of the ratio between side $\Gamma \Delta$ and side KA of the diagram 2 of Euclid's Optics. The supporting series are plotted in light gray and dotted lines, except for the one that has been selected as witness and shown in Figure 12, which is plotted with a dashed gray line. The average of all the supporting series is plotted in black. There are not unsupporting series.

I analyzed two variables: a) the angle between the shadow rays (which should become $0^{\circ}$ if they are parallel, as in the diagram of the manuscript), and b) the lens-shape of the circumference of the Earth.

The experiment was done 12 times. For both variables, the results are the same: 3 series had to be discarded, 9 support my hypothesis while only 1 does not. I plotted each variable in a different chart (Figures 17 and 18). In the first one (Figure 17) I measured the angle between the shadow rays. As the chart shows, on average, the rays become parallel around the seventh copy. In the second chart (Figure 18), I plotted the "lens-shape" of the Earth, for which I calculated the ratio between the horizontal and the vertical diameter of the Earth, and I plotted its logarithm.

In 9 cases, the rays become parallel and the Earth's sphere tends to acquire a lens-shape. The witness series shows that not only the Earth, but also the Sun acquires this lens-shape. As far as I know, this change is not found in any of the extant Greek manuscripts of Aristarchus's On Sizes and, nevertheless, it happens in almost every case in the experiment, constituting a minor anomaly. In addition, in the witness series the Moon has the same size as the Earth and Sun. Even if I did not measure this characteristic, it is precisely what happens in the diagram of the manuscript. In the experiment, it happened sometimes but not always. The similarity between the diagrams obtained through the experiment and that of the manuscript is astonishing (Figure 16). In this case the angle between the rays instantiates overspecification, and the lens-shape of the Earth is a case of indifference to visual accuracy.

\section{Concluding remarks}

I have shown that the two main characteristics that Saito and Sidoli [2012: 140-143] have identified in the diagrams of medieval copies of ancient manuscripts, i.e., overspecification and indifference to visual accuracy, could be the result of the transmission process, i.e., of the accumulated unintentional alterations 
0

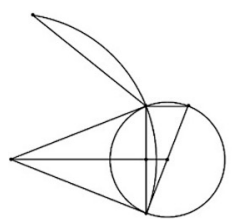

3

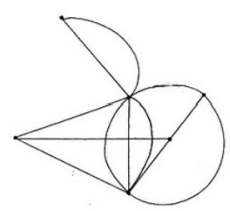

6

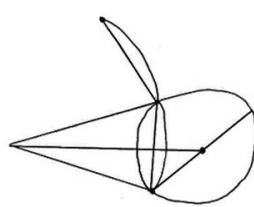

9

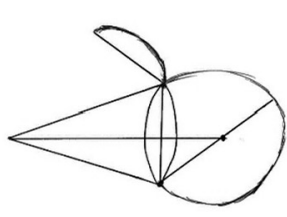

12

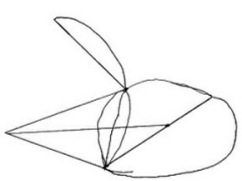

15

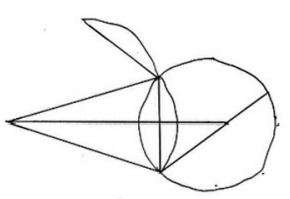

18

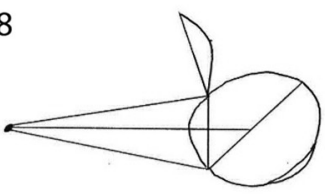

1

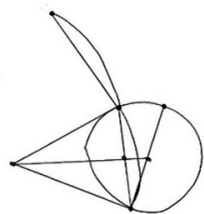

4

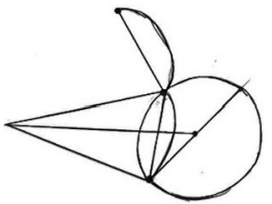

7

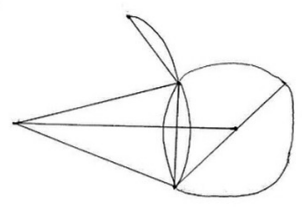

10

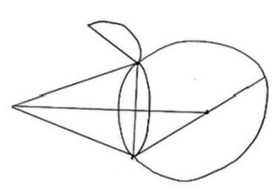

13

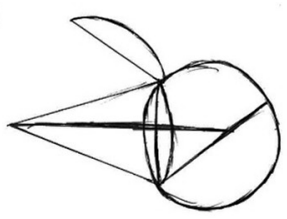

16

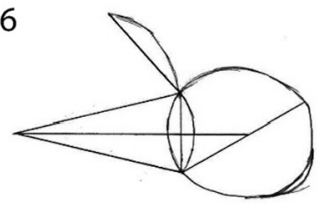

19

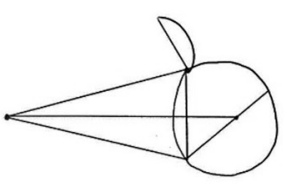

2

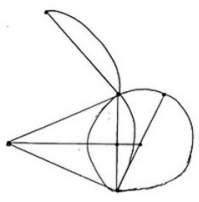

5

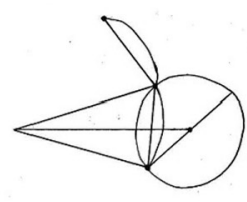

8

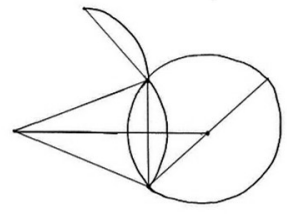

11

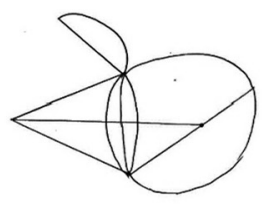

14

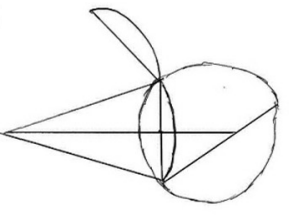

17

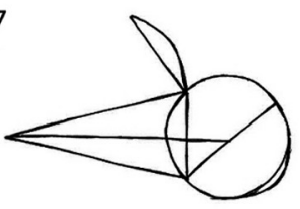

M

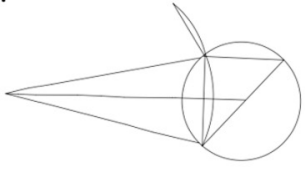

Figure 14. Reproduction of a witness series of the drawings copying the diagram of proposition 11 of Aristarchus's On the Sizes and Distances of the Sun and Moon. Starting diagram (0), inspired by Heath [1913, 387]; final diagram (M): Vatican 204, f. 114r. The drawings have been rotated and resized to fit in the assigned space.

copy after copy. In my analysis, I showed A) three cases related to overspecification ${ }^{17}$ and B) three cases of indifference to visual accuracy not related with symmetry. With respect to A: a1) the base $\mathrm{B} \Delta$ of the triangle $\mathrm{B} \Delta \mathrm{E}$ becomes perpendicular to line $\mathrm{A} \Gamma$ in the mentioned diagram of book $\mathrm{V}$ of Ptolemy's Almagest; $\mathrm{a} 2$ ) the segments $\mathrm{BO}$ and $\mathrm{BA}$ of the two cones become equal, making both cones to have the same height in the

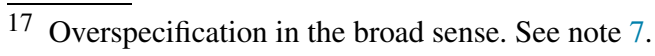

Please cite this article in press as: Carman, C.C. Accounting for overspecification and indifference to visual accuracy in manuscript diagrams: A tentative explanation based on transmission. Hist. Math. (2018), 


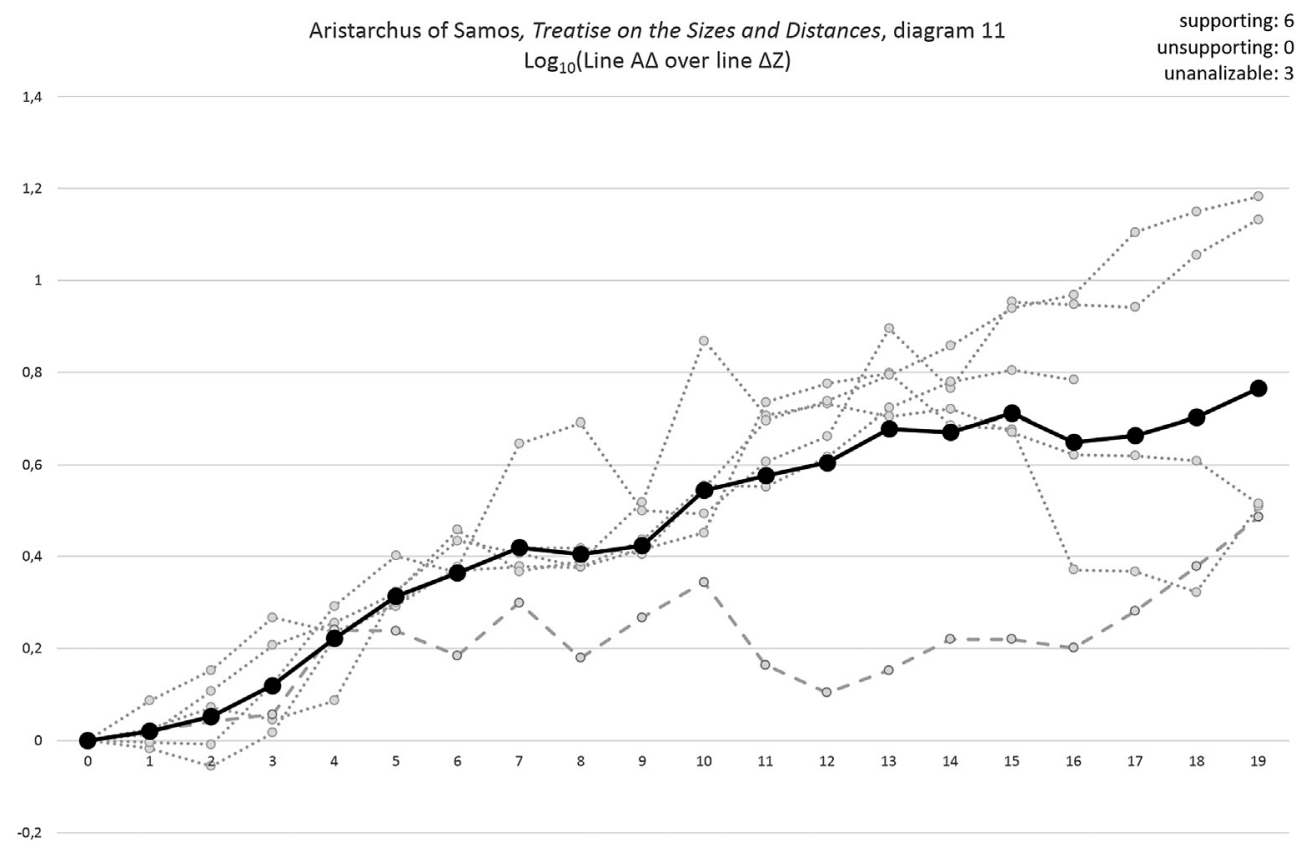

Figure 15. The chart shows the change throughout the copies of the logarithm of the ratio between line $\mathrm{A} \Delta$ and line $\Delta \mathrm{Z}$ of the diagram of the proposition 11 of Aristarchus's On Sizes. The unsupporting series is individually plotted in dark gray, the supporting series are plotted in light gray and dotted lines, except for the one that has been selected as witness and shown in Figure 14, which is plotted with a dashed gray line. The average of all the supporting series is plotted in black. There are not unsupporting series.

diagram of proposition 3 of Aristarchus's On Sizes; and a3) the shadow rays $\Delta \mathrm{H}$ and ZK become parallel in the diagram of proposition 14 of Aristarchus's On Sizes. With respect to B: b1) sides $\Gamma \Delta$ and K $\Lambda$ of two triangles become unequal in the diagram of proposition 2 of Euclid's Optics; b2) lines A $\Delta$ and $\Delta \mathrm{Z}$ in the diagram of proposition 11 of Aristarchus's On Sizes also become unequal; and b3) the sphere of the Earth in diagram of proposition 14 of Aristarchus's On Sizes acquires a lens shape.

The aim of this paper was to offer a new solution to why diagrams in medieval manuscripts show overspecification and indifference to visual accuracy within the framework of the history of science. My suggestion is that this feature is not due to the way ancient authors made their own diagrams, but to the process of transmission. This point, I hope, is persuasively shown through the series of experiments I presented and analyzed. It is reasonable to assume that the pattern of the changes found in the experiments is the product of some psychological mechanisms. Gestalt psychology is likely the most natural framework to explain these mechanisms. ${ }^{18}$ Some cases of overspecification can be explained, for example, recurring to the law of Good Gestalt, also called of Prägnanz, or to the law of symmetry. ${ }^{19}$ The same could be argued with regards to some cases of indifference to visual accuracy. ${ }^{20}$

There is also a wide range of visual motor Gestalt tests that, even if they are not exactly the same and could not by themselves prove my point, could certainly be related to the one used in my research. In some of these tests the subject is always asked to copy from the original, i.e., without serial reproductions. Many

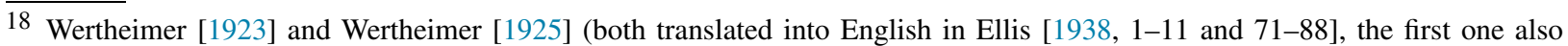
translated in an abridged version in Beardslee and Wertheimer [1958, 115-135]), Koffka [1922], Koffka [1936] and Köhler [1970].

19 For example, see Wertheimer [1925, 79], Beardslee and Wertheimer [1958, 125] and Koffka [1936, 140-141] for angles close to but not right, perceived as right angles, and Koffka [1936, 231-232] for ellipses perceived as circles and trapezoids as rectangles.

20 See the similarity of the effect explained by Köhler [1970, 170-171] and by Fuchs [1923] (translated into English in Ellis [1938, 102-103]) and that of line $\Gamma \Delta$ becoming greater than $\mathrm{K} \Lambda$ in the diagram of proposition 2 of Euclid's Optics. 
0

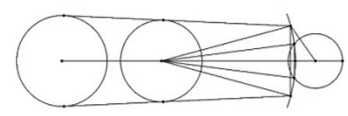

3

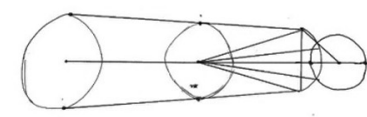

6

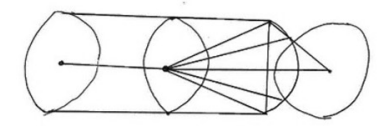

9

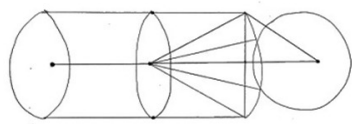

12

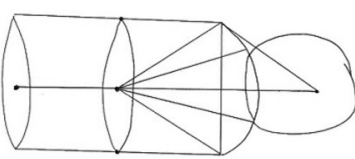

15

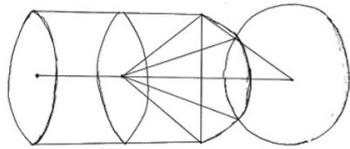

18

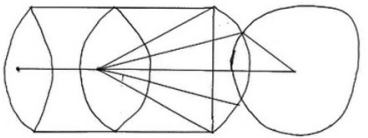

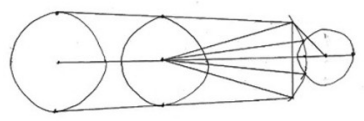

4

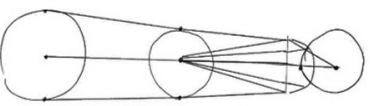

7

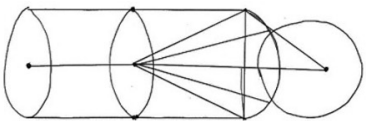

10

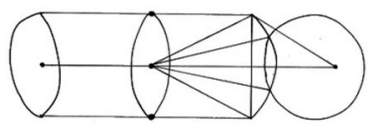

13

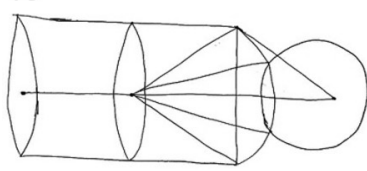

16

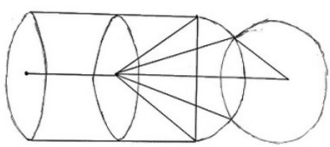

19

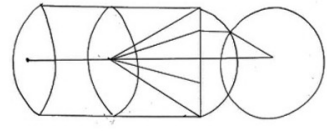

2

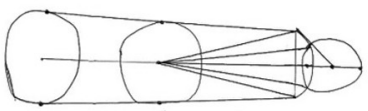

5

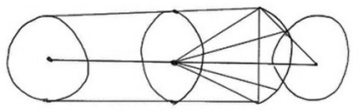

8

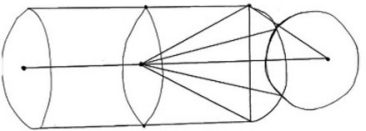

11

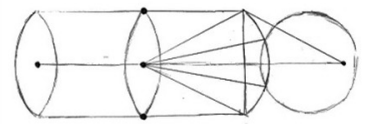

14

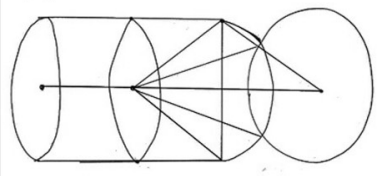

17

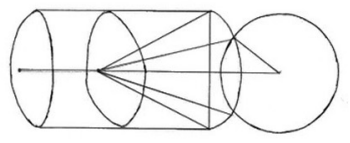

M

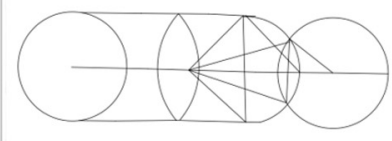

Figure 16. Reproduction of a witness series of the copies of the diagram of proposition 14 of Aristarchus's On the Sizes and Distances of Sun and Moon. I drew the starting diagram (0); final diagram (M): Vatican 204, f. 116v. The drawings have been rotated and resized to fit in the assigned space.

of them involve memory, i.e., the subject has to remember the diagram that she saw and reproduce it later, like the visual designs test from Graham and Kendall [1960a and 1960b], the visual retention test of Arthur Benton [1945], or the test of copying a complex figure of Rey [1941] and Osterrieth [1944]. Other tests, like the famous Bender test [Bender, 1938], not involving memory, aim at detecting the degree of maturation of a child or certain pathologies in children and adults. Finally, there are other tests that actually use series of copies and try to discover certain patterns in the series [Barlett, 1932, 177-185]. 


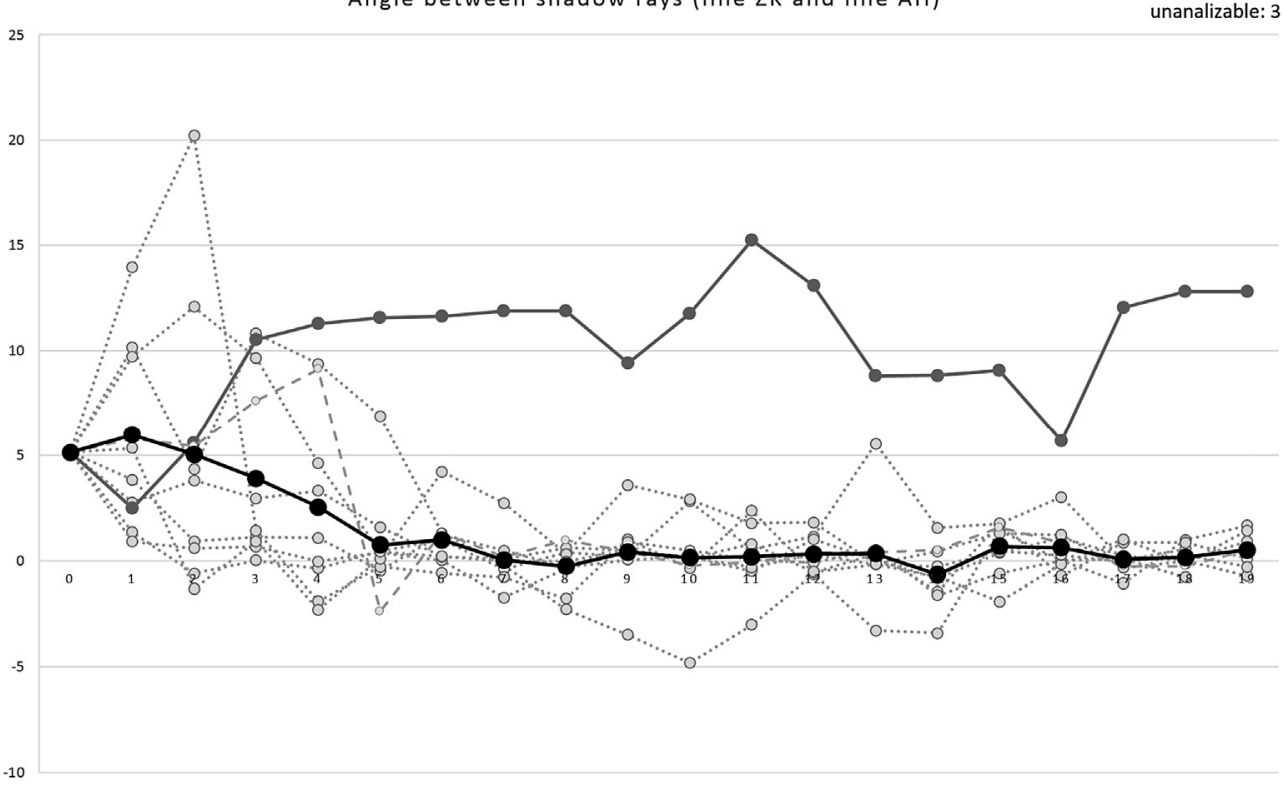

Figure 17. The chart shows the change throughout the copies of angle between shadow rays (line $\mathrm{ZK}$ and line $\mathrm{AH}$ ) of the diagram of proposition 14 of Aristarchus's On Sizes. The unsupporting series is individually plotted in dark gray, the supporting series are plotted in light gray and dotted lines, except for the one that has been selected as witness and shown in Figure 16, which is plotted with a dashed gray line. The average of all the supporting series is plotted in black.

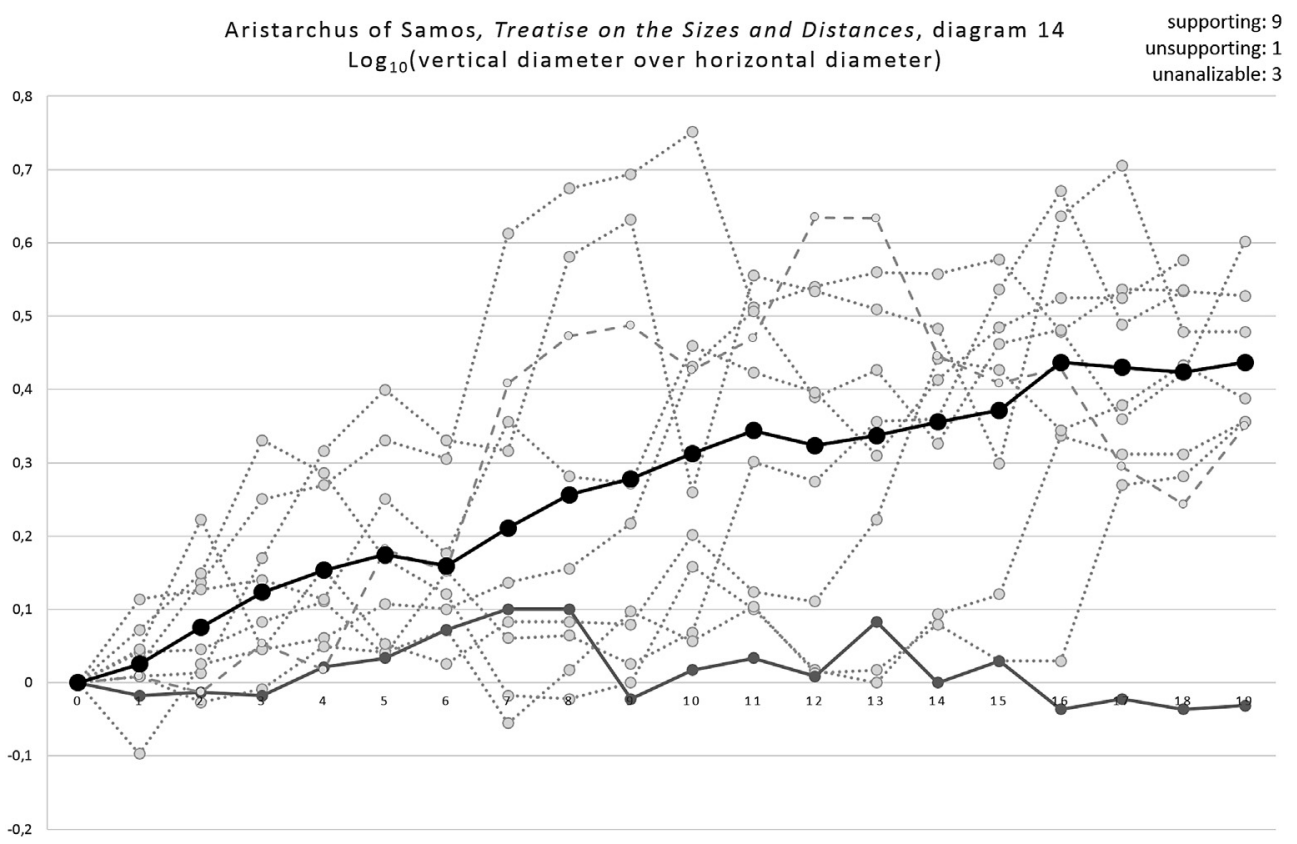

Figure 18. The chart shows the change throughout the copies of the logarithm of the ratio between the vertical and the horizontal diameter of the ellipse representing the Earth in the diagram of proposition 14 of Aristarchus's On Sizes. The unsupporting series is individually plotted in dark gray, the supporting series are plotted in light gray and dotted lines, except for the one that has been selected as witness and shown in Figure 16, which is plotted with a dashed gray line. The average of all the supporting series is plotted in black. 
Further studies could involve an in-depth statistical analysis of the rate of change of important observables in medieval manuscripts' diagrams in comparison to what can be reproduced in controlled conditions, including an evaluation of the effect of cultural context and education level of copyists among others. Such analysis, together with the psychological explanations, is beyond the aim of this paper, and I do not find it necessary for showing my suggestion that the overspecification and indifference to visual accuracy found in medieval manuscripts are produced during transmission, and so, probably, not due to Greek authors themselves. $^{21}$

\section{Acknowledgments}

I would like to thank all my colleagues both at the Universidad Nacional de Quilmes (UNQ) and the Pontificia Universidad Católica Argentina (UCA), who kindly allowed me to run the experiment with their students, as well as to the students who generously invested their time in the experiment: Leonardo Caviglia and Paula Carman (UCA), and Santiago Ginnobili and Lucía Federico (UNQ). I would also like to thank my Philosophy students at UNQ (second term, 2016), with whom I first tried the experiment. They were very enthusiastic and generous in allowing me to devote many hours of the course to testing different diagrams. Many discussions with Mariano Sigman and Hernán Grecco helped me to improve the methodology of the experiment. Ignacio Aguinalde gave me important guidance into the psychological bibliography. Several preliminary drafts of the paper were discussed with Daniel Blanco, Anibal Szapiro, Gonzalo Recio, Diego Pelegrin and Gustavo Zelioli. I also thank the comments of Alexander Jones, Daryn Lehoux and Nathan Sidoli who attended a conference in which I present this paper, the Fourth International Workshop on Epistemology and Astronomy, July, Rio de Janeiro, Brazil. This research was supported by the Research Projects PICT-2014-1741, PICT-2014-0775 and PICT-2016-4487 of the Agencia Nacional de Promoción de Científica y Tecnológica of Argentina.

\section{References}

\section{Manuscripts}

Vatican 204: Bibliotheca Apostolica Vaticana. Gr. 204. Ninth-tenth century.

Vatican 180: Bibliotheca Apostolica Vaticana. Gr. 180. Tenth century.

\section{Modern scholarship}

Acerbi, F., 2017. The mathematical Scholia Vetera to Almagest I.10-15. With a critical edition of the diagrams and an interpretation of their symmetry properties. SCIAMVS 18, 133-259.

Bartlett, F.C., 1932. Remembering: A Study in Experimental and Social Psychology. Cambridge University Press, Cambridge.

Beardslee, D.C., Wertheimer, M. (Eds.), 1958. Readings in Perception. Van Nostrand, Princeton.

Bender, L., 1938. A Visual-Motor Gestalt Test and Its Clinical Use. American Orthopsychiatric Association Monograph Series, vol. 3. American Orthopsychiatric Association, New York.

Benton, A.L., 1945. A visual retention test for clinical use. Arch. Neurol. Psychiatry 54, 212-216.

Berggren, J.L., Sidoli, N., 2007. Aristarchus's On the Sizes and Distances of the Sun and the Moon: Greek and Arabic texts. Arch. Hist. Exact Sci. 61, 213-254.

Besthorn, R.O., Heiberg, J.L., Junge, G., Raeder, J., Thomson, W., 1897-1932. Codex Leidenis 399, 1: Euclidis elementa ex interpretatione al-Hadschdschadschii cum commentariis al-Narizii. Copenhagen. Reprint: Sezgin F., (Ed.). Institut für Geschichte der Arabisch-Islamischen Wissenschaften. Frankfurt am Main, 1997.

$\overline{21}$ An anonymous referee pointed out that Acerbi [2017, 244-246] offers, in an appendix, a similar idea. Acerbi's paper was published during the evaluation process of this paper. Nathan Sidoli provided me a pre-print copy to consider his proposal, which is limited only to overspecification and is certainly not identical with my suggestion. It has, however, some similarities with it. 
Carman, C., 2014. Two problems in Aristarchus's treatise On the Sizes and Distances of the sun and moon. Arch. Hist. Exact Sci. 68, 35-65.

Czinczenheim, C., 2000. Edition, traduction et commentaire des Sphériques de Théodose. Atelier National de Reproduction des Thèses. Lille. Thèse de doctorat de l'Universite Paris IV.

Decorps-Foulquier, M., 1999. Sur les figures du traité des Coniques d'Apollonius de Pergé édité par Eutocius d'Ascalon. Rev. Hist. Math. 5, 61-82.

Ellis, W., 1938. A Source Book of Gestalt Psychology. Routledge \& Kegan Paul, London.

Fowler, D., 1999. The Mathematics of Plato's Academy. Oxford University Press, Oxford.

Fuchs, W., 1923. Experimentelle Untersuchungen über die Aenderung von Farben unter dem Einfluss von Gestalten (“Angleichungserscheinungen"). Z. Psychol. 92, 249-325. Translated into English in Ellis 1938: 95-103.

Graham, F.K., Kendall, B.S., 1960a. Memory-for-designs test: revised general manual. Percept. Mot. Skills 1, $147-188$.

Graham, F.K., Kendall, B.S., 1960b. Performance of brain-damaged cases on a memory-for-designs test. J. Abnorm. Soc. Psychol. 41, 303-314.

Heath, T., 1913. Aristarchus of Samos: The Ancient Copernicus. Clarendon Press, Oxford.

Heiberg, J.L., 1891-1893. Apollonius Pergaeus quae Graece exstant cum commentariis antiquis, 2 vols. Teubner, Leipzig.

Heiberg, J.L., 1927. Theodosius Tripolites Spaerica. Weidmann, Berlin.

Heiberg, J.L., Menge, H., 1895. Euclidis, Opera Omnia, vol. VII. Teubner, Leipzig.

Jones, A., 1986. Pappus of Alexandria: Book 7 of the Collection. Springer, New York.

Jones, A., 1994. Peripatetic and Euclidean theories of the visual ray. Physis. Rivista internazionale di storia della scienza 31, 47-76.

Knorr, W., 1994. Pseudo-Euclidean reflections in ancient optics: a re-examination of textual issues pertaining to the Euclidean Optica and Catoptrica. Physics 31, 1-45.

Koffka, K., 1922. Perception: an introduction to the Gestalt-theorie. Psychol. Bull. 19, 531-585.

Koffka, K., 1936. Principles of Gestalt Psychology. Kegan Paul, London.

Köhler, W., 1970. Gestalt Psychology. An Introduction to New Concepts in Modern Psychology. Liverright, New York.

Lejeune, A. (Ed.), 1956. L'optique de Claude Ptolémée dans la version latine d'après l'arabe de l'émir Eugène de Sicile. Édition critique et exégétique. Publications Universitaires de Louvain, Louvain.

Lejeune, A., 1989. L'Optique de Claude Ptolémée dans la version latine d'après l'arabe de l'émir Eugène de Sicile. Leiden (Reprint, with new French translation, of Lejeune [1956]).

Mascellani, P., Napolitani, P.D., Gavagna, V., 2005. M2.5.2 - Minutes of the workshop on "The Problem of Diagrams and Drawings Criticism in Mathematical Texts". A workshop held in Pisa. Report Version 1.0. Pisa.

Menge, H., 1916. Euclidis phaenomena et scripta musica, Opera omnia vol. viii. Teubner, Leipzig.

Mogenet, J., 1950. Autolycus de Pitane, histoire du texte suivie de l'édition critique des traités de la Sphère en mouvement et des levers et couchers. Université de Louvain. Recueil de Travaux d'Histoire et de Philologie, 3e sér. fasc. 37. Louvain.

Netz, R., Noel, W., 2007. The Archimedes Codex. How a Medieval Prayer Book Is Revealing the True Genius of Antiquity's Greatest Scientist. Da Capo Press, Philadelphia.

Netz, R., 1999. The Shaping of Deduction in Greek Mathematics. Cambridge University Press, Cambridge.

Netz, R., 2004. The Works of Archimedes: vol. I. The Two Books On the Sphere and the Cylinder. Cambridge University Press, Cambridge.

Netz, R., 2012. The texture of Archimedes' writings: through Heiberg's Veil. In: Chemla, K. (Ed.), The History of Mathematical Proof in Ancient Traditions. Cambridge University Press, Cambridge, pp. 163-205.

Netz, R., 2015. Were there Epicurean mathematicians? In: Inwood, B. (Ed.), Oxford Studies in Ancient Philosophy, vol. 49. Oxford University Press, Oxford, pp. 283-320.

Neugebauer, O., 1975. A History of Ancient Mathematical Astronomy. Studies in the History of Mathematics and Physical Sciences, vols. 1, 3. Springer, Berlin.

Osterrieth, P.A., 1944. Le test de copie d'une figure complex: contribution à l'étude de la perception et de la mémoire. Arch. Psychologie 30, 286-356. 
Raynaud, D., 2014. Building the stemma codicum from geometric diagrams. A treatise on optics by Ibn al-Haytham as a test case. Arch. Hist. Exact Sci. 68, 207-239.

Raynaud, D., 2016. A Critical Edition of Ibn al-Haytham's On the Shape of the Eclipse. Springer, Berlin.

Rey, A., 1941. L'examen psychologique dans les cas d'encephalopathie traumatique (Les problems). Arch. Psychologie 28, 215-285.

Rome, A., 1931-1943. Commentaires de Pappus et Théon d'Alexandrie sur l'Almageste, 3 vols. Biblioteca Apostolica Vaticana, Studi e Testi 72, 54 and 106. Rome.

Saito, K., 2006. A preliminary study in the critical assessment of diagrams in Greek mathematical works. SCIAMVS 7 , 81-144.

Saito, K., 2012. Traditions of the diagram, tradition of the text: a case study. Synthese 186, 7-20.

Saito, K., Sidoli, N., 2012. Diagrams and arguments in ancient Greek mathematics: lessons drawn from comparisons of the manuscript diagrams with those in modern critical editions. In: Chemla, K. (Ed.), The History of Mathematical Proof in Ancient Traditions. Cambridge University Press, Cambridge, pp. 135-162.

Sidoli, N., 2007. What we can learn from a diagram: the case of Aristarchus's on the sizes and distances of the Sun and Moon. Ann. Sci. 64, 525-547.

Sidoli, N., 2015. Mathematics education. In: Bloomer, W.M. (Ed.), A Companion to Ancient Education. WileyBlackwell, Oxford, pp. 387-400.

Toomer, G.J., 1988. Ptolemy’s Almagest. Princeton University Press, Princeton.

Wertheimer, M., 1923. Untersuchungen zur Lehre von der Gestalt II. Psychol. Forschung 4, 301-350.

Wertheimer, M., 1925. Über Gestalttheorie (an address before the Kant Society, Berlin, 17th December, 1924). Erlangen.

Christián C. Carman is Professor and Researcher at the Universidad Nacional de Quilmes, Argentina, and research member of the National Research Council of Argentina (CONICET). He works on topics related to philosophy of science (particularly the scientific realism debate) as well as history of ancient astronomy, mainly related to the Antikythera mechanism and with the calculations of the distances of the sun and moon. He recently published "The first Copernican was Copernicus: the difference between Pre-Copernican and Copernican heliocentrism" (Archive for History of Exact Sciences 72(1) (January 2018) 1-20). 